\title{
Dietary effect of mead acid on DMBA-induced breast cancer in female Sprague-Dawley rats
}

\author{
YUICHI KINOSHITA $^{1 *}$, MASAHIRO YOSHIOKA $^{2 *}$, YUKO EMOTO $^{3}$, \\ TAKASHI YURI ${ }^{2}$, MICHIKO YUKI $^{4}$, CHIHIRO KOYAMA $^{5}$, AKIKO TAKENOUCHI $^{5}$, \\ KEI HAMAZAKI ${ }^{6}$, AIRO TSUBURA ${ }^{7}$ and KATSUHIKO YOSHIZAWA ${ }^{5}$ \\ ${ }^{1}$ Division of Central Laboratory of Medicine and Pathology, Wakayama Medical University Hospital, \\ Wakayama 641-8510; ${ }^{2}$ Department of Nutrition, Koshien University, Takarazuka, Hyogo 665-0006; \\ ${ }^{3}$ Ethics Review Center, Kansai Medical University, Hirakata, Osaka 573-1010; ${ }^{4}$ Department of Pathology, \\ Hyogo College of Medicine, Nishinomiya, Hyogo 663-8501; ${ }^{5}$ Department of Innovative Food Sciences, \\ School of Food Sciences and Nutrition, Mukogawa Women's University, Nishinomiya, Hyogo 663-8558; \\ ${ }^{6}$ Department of Public Health, Faculty of Medicine, University of Toyama, Toyama 930-0194; \\ ${ }^{7}$ Department of Pathology, Osaka Prefectural Saiseikai Izuo Hospital, Osaka 551-0032, Japan
}

Received June 22, 2020; Accepted August 31, 2020

DOI: $10.3892 / \mathrm{ijfn} .2020 .7$

\begin{abstract}
In the present study, the dietary effects of mead acid (MA; 5,8,11-eicosatrienoic acid) on 7,12-dimethylbenz[a]anthracene (DMBA)-induced breast cancer in female Sprague-Dawley rats were examined. The 2.4 and $4.8 \% \mathrm{MA}$ diets were commenced when the rats were 6 weeks of age. DMBA was administered by a single oral ingestion when the rats were 7 weeks of age, and the rats were maintained on the respective diets until 19 weeks of age. Tumor weight, histopathology, cell kinetics, and the fatty acid composition in breast tissue and serum were examined. In the control (CTR) group, the DMBA-exposed rats were fed a basal $\operatorname{diet}(0 \% \mathrm{MA})$. The results revealed that there were no significant differences in tumor incidence, cell kinetics and in the N-6/N-3 ratio in breast tissue between the groups. Only the $\mathrm{N}-6 / \mathrm{N}-3$ ratio of fatty acid composition in serum was significantly decreased in the $2.4 \%$ MA diet group. In previous studies, the $2.4 \% \mathrm{MA}$ diet was shown to suppress $N$-methyl- $N$-nitrosourea-induced luminal A mammary cancer by decreasing cancer cell proliferation. The findings of the present study differ from those of previous studies with different breast cancer models. To further clarify the effects of MA against breast carcinogenesis, further investigations with different experimental breast cancer models are recommended.
\end{abstract}

Correspondence to: Professor Katsuhiko Yoshizawa, Department of Innovative Food Sciences, School of Food Sciences and Nutrition, Mukogawa Women's University, 6-46 Ikebiraki-cho, Nishinomiya, Hyogo 663-8558, Japan

E-mail: yoshizak@mukogawa-u.ac.jp

*Contributed equally

Key words: breast cancer, 7,12-dimethylbenz[a]anthracene, polyunsaturated fatty acid, mead acid, rat

\section{Introduction}

Breast cancer is the most frequent type of tumor occurring in women globally and its incidence has recently increased (1). Epidemiological investigations have demonstrated an association between the incidence of breast cancer and dietary habits. For example, a high-fat diet has been shown to increase the risk of breast cancer $(2,3)$. Notably, polyunsaturated fatty acids (PUFAs) are highly associated with mammary carcinogenesis. For example, n-3 fatty acids, such as eicosapentaenoic acid (EPA) and docosahexaenoic acid (DHA) have been shown to suppress the growth of breast cancer in vitro and in vivo (4-6). In contrast to these findings, n- 6 fatty acids, such as linoleic acid (LA) and arachidonic acid (AA) have been shown to promote the development of breast cancer $(7,8)$. The association between fatty acids and carcinogenesis thus needs to be clarified, in order to establish new dietary habits which may prevent cancers. The effects of $n-9$ fatty acids on breast carcinogenesis are not yet well understood.

Mead acid (MA) is a 20:3 n-9 fatty acid (5,8,11-eicosatorienoic acid) that was characterized by Mead and Slaton (9). MA can be found in minor quantities in the plasma and tissues of adult mammals and is synthesized from oleic acid (OA;18:1 n-9) by elongation and desaturation when essential n-3 and n-6 PUFAs are deficient $(10,11)$.

The anticancer effects of MA were previously investigated against luminal type A breast cancer (12). MA was found to suppress the growth of breast cancer cells (KPL-1) in vitro. The dietary administration of MA was also shown to suppress the growth of transplanted KPL-1 tumors in nude mice (12). In another previous in vivo study using female rats, breast cancer was induced by the carcinogen, $N$-methyl- $N$-nitrosourea (MNU), and MA was shown to suppress the growth of breast tumor xenografts (13).

In addition to the present study, to the best of our knowledge, only one previous study has been conducted to date reporting 
that MA exerts an anticancer effect against breast cancer (14). Heyd and Eynard demonstrated that MA suppressed the proliferation of the breast cancer cell line, MCF-7 (14). In their study, they further examined the influence of MA on the bladder cancer cell line, T-24, and on the colon cancer cell line, HRT-18. Unlike the data obtained with MCF-7 cells, MA was shown to promote the growth of HRT-18 cells. In the presence of a high cell density, MA increased the proliferation of T-24 cells (14). Opposite findings were noted (decreased proliferation) when the cell density was low (14).

MA has been shown to exert various effects depending on the cancer type. However, the ability of MA to affect the prevention of carcinogenesis is not yet well understood. To further investigate the anticancer effects and mechanisms of MA, which could lead to new practical applications, such as a novel therapeutic agent, dietary habits and functional foods, additional studies with different models are required. In the present study, the anticancer effects of MA were investigated in a rat model of 7,12-dimethylbenz[a] anthracene (DMBA)-induced breast cancer, as previously described (15).

\section{Materials and methods}

Diet. The experimental diets contained the same amounts of nutrients, but included different fatty acid compositions (Table I). In brief, the MA and control (CTR) diets were modifications of the AIN-76 diet. The MA diet contained 5 or $10 \%$ SUNTGM33, which in turn contains $48 \%$ MA $(12,13)$. SUNTGM33 is a microbial oil obtained by fungal fermentation (16). The CTR diets contained 5 or $10 \%$ olive oil (Nakalai Tesque), which contained $74.7 \%$ oleic acid (OA). OA is a precursor of MA. The composition of SUNTGM33 and olive oil have been described in our previous studies $(12,13)$. The experimental diets contained 2.4 or $4.8 \%$ MA, while the CTR diet did not contain MA. The concentration of MA in the experimental diet was consistent with our previous studies $(12,13)$. The highest concentration of MA $(4.8 \%)$ in the diet contained almost the same amount of MA, which was considered the upper limit on the blend material level for the diet used in rat feeding studies.

Carcinogen. DMBA was obtained in powder form from Eastman Chemical. Prior to its use, DMBA was dissolved in sesame oil at $120^{\circ} \mathrm{C}$ (DMBA $1,000 \mathrm{mg} / 50 \mathrm{ml}$ sesame oil). A single dose of $80 \mathrm{mg} / \mathrm{kg}$ body weight was administered orally (17). The same amount of sesame oil without DMBA was administered to the animals in the CTR group.

Animals and experimental procedures. The study protocol and animal procedures were approved by the Animal Care and Use Committee of Kansai Medical University, Hirakata, Osaka, Japan (permit no. 13-060). Throughout the experiments, the animals were housed and treated in accordance with the Guidelines for Animal Experimentation of Kansai Medical University. In the present study, the following criteria for humane endpoints were also used (NIH guidelines for endpoints in animal study proposals): i) A tumor burden $>10 \%$ of the animal body weight; ii) the tumor should not exceed $40 \mathrm{~mm}$ in any one dimension; iii) tumors that become ulcerated, necrotic or infected; iv) tumors that interfere with the eating ability or impair the ambulation of the animals.

In brief, 86 female Sprague-Dawley rats $[\mathrm{Crl}: \mathrm{CD}(\mathrm{SD})$, 6 weeks old] were purchased from Charles River Laboratories Japan. They were housed in groups of 4 or 5 in plastic cages with paper bedding (Paper Clean; Japan SLC, Inc.) in a specific pathogen-free environment maintained at $22 \pm 2^{\circ} \mathrm{C}$ and at $60 \pm 10 \%$ relative humidity with a 12 -h light/dark cycle (lights on at 8:00 a.m. and lights off at 8:00 p.m.). In the experiment with $2.4 \% \mathrm{MA}$, the rats were randomly divided into 4 groups as follows: The CTR + sesame oil $(n=5), C T R+$ DMBA (n=13), 2.4\% MA + sesame oil $(n=5)$ and $2.4 \% \mathrm{MA}+$ DMBA $(n=13)$ groups. In the experiment with $4.8 \% \mathrm{MA}$, the rats were divided into 4 groups as follows: CTR + sesame oil $(\mathrm{n}=10), 4.8 \% \mathrm{MA}+$ sesame oil $(\mathrm{n}=10)$, CTR + DMBA $(\mathrm{n}=15)$ and $4.8 \%$ MA + DMBA $(n=15)$ groups.

Fresh sterilized stocks of the pellet diet were provided to the animals twice a week starting at 6 weeks of age. The previous pellets were discarded to minimize the ingestion of oxidized fatty acids. The animals in the experimental groups received DMBA, whereas the animals in the CTR groups received sesame oil at 7 weeks of age and all animals remained on the same diets for the remaining duration of the experiments (until 19 weeks of age). The experimental diets and water were available freely. During the dosing period, the dose of the diet ingested, body weight and tumor volume were measured once a week. The tumor volume was calculated using the standard formula: $\mathrm{Width}^{2} \mathrm{x}$ length $\mathrm{x} 0.5$. The tumor volume measurement was used for monitoring of tumor incidence and growth. Prior to sacrifice, all rats were anesthetized with isoflurane (Wako Pure Chemical Industries, Ltd.). Before necropsy, the isoflurane was made to soak into paper and was put in closed chamber. Subsequently, rats were anesthetized in a pervasive chamber of isoflurane which was vaporized. A total of $4 \%$ of isoflurane was used for the induction of anesthesia and blood was sampled by inferior vena cava puncture. Subsequently, the animals were sacrificed by exsanguination and aortic transection. At necropsy, all organs were examined macroscopically and the breast tissue and tumors were examined histologically. The tissues were fixed in $10 \%$ neutral-buffered formalin, embedded in paraffin and finally stained with hematoxylin and eosin (Wako Pure Chemical Industries, Ltd.). Cell kinetics were also assessed. The serum samples and the sections of the non-tumor breast tissues were used for fatty acid analysis. During the examination of the animals receiving the $4.8 \% \mathrm{MA}$ diet, fatty acid analysis was not carried out.

Cell kinetics. The cell kinetics (cell proliferation activity and apoptosis) in the 6 largest DMBA-induced tumors were evaluated. The cell proliferative activity was evaluated using anti-Ki-67 antibody (cat. no. 418071, prediluted, clone SP6, Nichirei Biosciences). The incubation condition was $1 \mathrm{~h}$ at room temperature. The induction of apoptosis was evaluated by the anti-phospho-histone H2A.X ( $\gamma$-H2A.X) antibody (cat. no. 2577S, x100, clone Ser139, 1:100; Cell Signaling Technology, Inc.), an immunomarker of the DNA damage response. The incubation condition was $1 \mathrm{~h}$ at room temperature. Immunohistochemical analysis was performed with the Histofine MAX-PO for rats kit (Nichirei Biosciences) according to the manufacturer's protocol. Each slide was 
Table I. Composition of the experimental diets.

\begin{tabular}{|c|c|c|c|c|}
\hline \multirow[b]{2}{*}{ Component } & \multicolumn{2}{|c|}{ 2.4\% MA experimental group } & \multicolumn{2}{|c|}{ 4.8\% MA experimental group } \\
\hline & CTR diet & MA diet & CTR diet & MA diet \\
\hline Gasein & 20 & 20 & 20 & 20 \\
\hline DL-methionine & 0.3 & 0.3 & 0.3 & 0.3 \\
\hline Cornstarch & 43 & 43 & 38 & 38 \\
\hline$\alpha$-Cornstarch & 12 & 12 & 12 & 12 \\
\hline Sucrose & 10 & 10 & 10 & 10 \\
\hline Cellulose & 5 & 5 & 5 & 5 \\
\hline AIN-76 mineral mix & 3.5 & 3.5 & 3.5 & 3.5 \\
\hline AIN-76 vitamin mix & 1 & 1 & 1 & 1 \\
\hline Choline bitartrate & 0.2 & 0.2 & 0.2 & 0.2 \\
\hline SUNTGM33 & 0 & 5 & 0 & 10 \\
\hline Olive oil & 5 & 0 & 10 & 0 \\
\hline
\end{tabular}

Values are expressed in g/100 g diet. MA, mead acid; CTR, control.

scanned with a high-resolution digital scanner (NanoZoomer 2.0 Digital Pathology; Hamamatsu Photonics) to prepare the digital images (NDPI image). The NDPI image files were opened in color mode with the NDP.view software (Hamamatsu Photonics). The images were converted to the JPEG files (magnification, $\mathrm{x} 400$ ) in 5 randomly selected areas within each tumor and were analyzed by immunohistochemical staining, as previously described $(12,18,19)$. The $\mathrm{Ki}-67$ and $\gamma-\mathrm{H} 2 \mathrm{~A} . \mathrm{X}$ labeling indices were assessed by positive cells/1,000 cells as an index of cell kinetics.

Fatty acid analysis of serum and mammary tissue. The fatty acid composition of the total phospholipid fraction of serum was determined and mammary gland samples were extracted using the method described in the study by Bligh and Dyer (20). The total phospholipid fraction was separated by thin-layer chromatography. The compound 1,2-diheptadecanoyl-sn-glycero-3-phosphocholine (Avanti Polar Lipids, Inc.) was added as an internal standard. Total phospholipid fractions were transmethylated with HCL-methanol and subsequently, the fatty acid composition was analyzed by gas chromatography (GC-2014, Shimadzu Corporation) with a capillary column DB-225 $(0.25 \mathrm{~mm}$ x $30 \mathrm{~m}$ x $0.25 \mu \mathrm{m})$ (J\&M Scientific, Folsom). The system was controlled with the gas chromatography software (GC solution; Shimadzu Corporation). The fatty acid composition of the total lipid fraction of the non-tumor mammary gland was determined. Frozen tissues were thawed, minced and homogenized 3 times for $10 \mathrm{sec}$ in $8 \mathrm{ml}$ chloroform-methanol $(2: 1)$ by a polytron homogenizer (Kinematica). The fatty acid analysis of the total lipid content in the breast tissues was performed by a similar method as that described in the analysis of the serum and mammary glands, with the exception of excluding the separation step performed by thin-layer chromatography $(9,10,20)$.

Statistical analysis. The values are expressed as the means \pm standard error of the mean. The parameters body weight, tumor volume, tumor weight, fatty acid composition and the percentage of Ki-67-positive and $\gamma$-H2A.X-positive cells among the groups were analyzed using the Student's t-test. The incidence of breast cancer was analyzed using a $\chi^{2}$ test.

\section{Results}

Host animals. During the dosing period, the daily dose of food ingestion was compatible among the different groups. The parameter body weight did not reveal significant differences when the $2.4 \%$ MA diet was used, while in the $4.8 \%$ MA diet experimental protocol, the body weight in the group administered the $4.8 \%$ MA diet and exposed to DMBA was significantly decreased compared with that of the group administered the $4.8 \%$ MA diet and given sesame oil (Fig. 1).

Mammary carcinogenesis. All mammary tumors were examined and confirmed histologically as mammary cancers. At the end of the experimental period, although the tumor incidence in both the 2.4 and $4.8 \%$ MA diet groups was lower than that noted in the CTR diet groups, the differences were not significant (Fig. 2). The mean values of DMBA-induced breast tumor weight in the CTR diet and 2.4\% MA diet groups were $1,323 \pm 251.4 \mathrm{mg}$ and $1,019.3 \pm 178.6 \mathrm{mg}$, respectively, while the final average breast tumor weight in the CTR diet and $4.8 \%$ MA diet groups was $941.3 \pm 231.4 \mathrm{mg}$ and $1,235.6 \pm 208.4 \mathrm{mg}$, respectively. Neither of these groups demonstrated a significant difference (Table II and Fig. 3). The mean values for tumor volume in the CTR diet and $2.4 \%$ MA diet groups were $1,582 \pm 451 \mathrm{~mm}^{3}$ (maximum diameter, $29 \mathrm{~mm}$ ) and 1,520 $\pm 397 \mathrm{~mm}^{3}$ (maximum diameter, $31 \mathrm{~mm}$ ), respectively, while the final average values for tumor volume in the CTR diet and $4.8 \%$ MA diet groups were $633 \pm 1301 \mathrm{~mm}^{3}$ (maximum diameter, $27 \mathrm{~mm}$ ) and $930 \pm 2,418 \mathrm{~mm}^{3}$ (maximum diameter, $32 \mathrm{~mm}$ ), respectively. Neither of these groups demonstrated a significant difference. The largest volume in the CTR diet and $2.4 \%$ diet groups were $7,406 \mathrm{~mm}^{3}$ (28 $\mathrm{mm}$ in diameter) and 

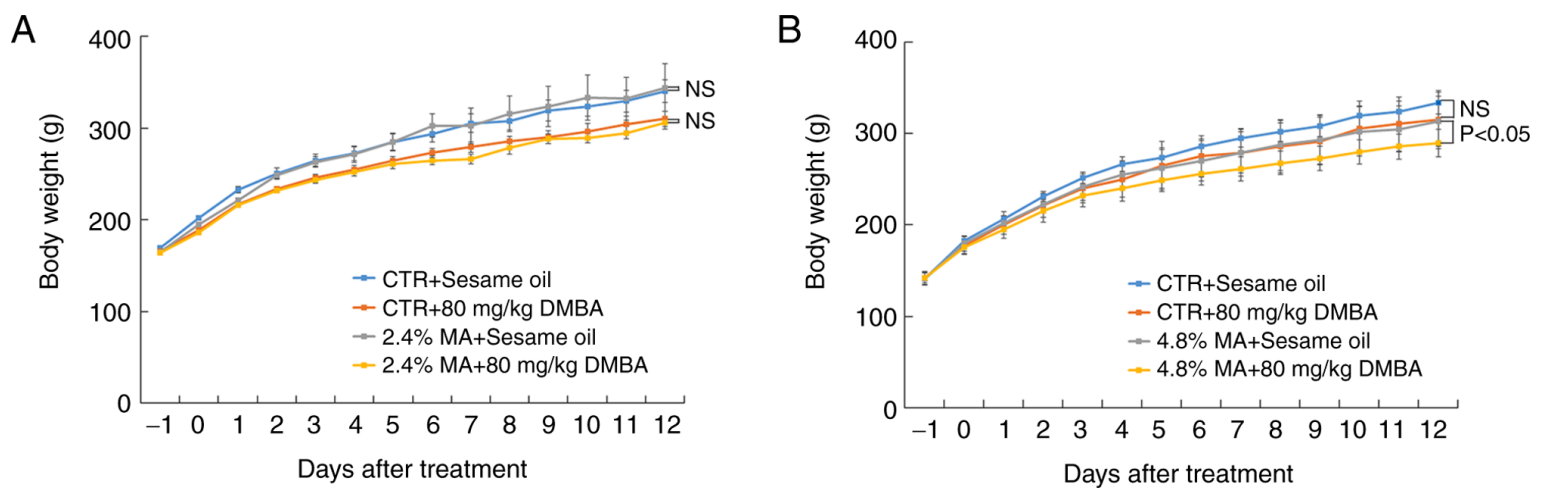

Figure 1. Changes in body weight of rats fed the CTR diet and 2.4\% MA diet. (A) There was not significant difference in final body weight between the $2.4 \%$ MA diet group and CTR diet group at the end of the experiment. (B) DMBA treatment significantly decreased the body weight with the $4.8 \%$ MA diet. NS, not significant; CTR, control; MA, mead acid; DMBA, 7,12-dimethylbenz[a]anthracene.
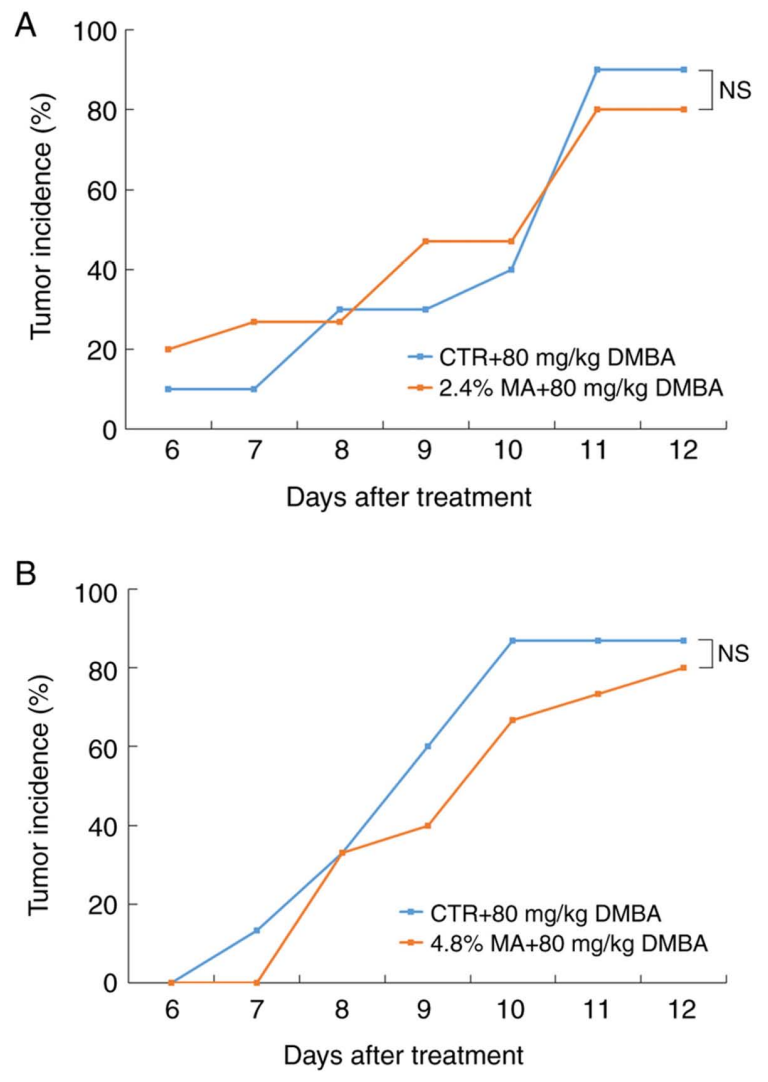

Figure 2. Effects of MA on the incidence of breast tumors during the dosing period. (A) There were not significant differences between the $2.4 \%$ MA and CTR diet. (B) The $4.8 \%$ MA diet also did not significantly influence the tumor incidence. NS, not significant; CTR, control; MA, mead acid; DMBA, 7,12-dimethylbenz[a]anthracene.

$10,478 \mathrm{~mm}^{3}$ (31 mm in diameter), respectively, while the largest tumor volumes in the CTR diet group and $4.8 \%$ MA diet groups were $5,832 \mathrm{~mm}^{3}$ (27 $\mathrm{mm}$ in diameter) and $10,240 \mathrm{~mm}^{3}(32 \mathrm{~mm}$ in diameter) respectively. The mean values of DMBA-induced breast tumor multiplicity in the CTR diet and $2.4 \%$ MA diet groups were $5.0 \pm 1.3$ and $4.1 \pm 0.3$, respectively, while the final average breast tumor multiplicity values in the CTR diet and $4.8 \%$ MA diet groups were $2.3 \pm 0.7$ and $2.0 \pm 0.3$, respectively. Neither of these groups demonstrated a significant difference (data not shown).
In the groups in which DMBA was not administered, the presence of breast tumors was not observed, in the presence of either the CTR or MA diet in both experimental settings. No conspicuous morphological differences were noted between the CTR diet and the MA diet groups. No lymph node metastasis was noted in any animal.

Proliferation and apoptotic ratio of DMBA-induced breast cancer. The percentages of Ki-67-positive cells and $\gamma$-H2A.X-positive cells from the CTR diet and MA diet groups were compared with regard to the ratio of proliferative cells and the apoptotic cell number. The proliferative cell number and apoptotic cell ratio are presented in Table III and Fig. 4. Although the MA diet exhibited a tendency to suppress cancer cell proliferation, the differences observed were not significant. In both experimental settings with the $2.4 \%$ MA and $4.8 \%$ MA diet, the ratio of apoptotic cells was exactly the same.

Fatty acid composition of serum and mammary tissue. The different diet groups exhibited different fatty acid compositions in serum and mammary tissues, reflecting the content of the respective diets. Exposure to DMBA did not affect the fatty acid composition. The n-3, n-6 and n-9 (MA) fatty acid composition levels in the serum of the animals receiving the $2.4 \% \mathrm{MA}$ diet were significantly increased compared with those noted in the CTR diet group, whereas the concentrations of OA, LA, AA and DHA were significantly decreased compared with those noted in the CTR + sesame oil group (Fig. 5A). The levels of $\mathrm{OA}$ and LA in the non-tumor mammary gland were significantly decreased and the level of AA in non-tumor mammary gland was significantly increased in the MA group compared with those noted in the CTR + sesame oil group (Fig. 5B). The changes in serum fatty acid composition resulted in a significant decrease in the $\mathrm{N}-6 / \mathrm{N}-3$ ratio in the $2.4 \%$ MA diet group (Fig. 6A). However, the N-6/N-3 ratio noted in the non-tumor breast tissue did not exhibit any marked changes (Fig. 6B).

\section{Discussion}

It is well known that there are a number of risk factors for breast cancer (e.g., an advanced age or viral infection) (21). The dietary quality and habits are also one of the factors affecting breast cancer (e.g., the consumption of red meat, 
Table II. Weight of DMBA-induced breast cancer (mg).

\begin{tabular}{|c|c|c|c|c|}
\hline & \multicolumn{2}{|c|}{$2.4 \%$ MA experimental group } & \multicolumn{2}{|c|}{ 4.8\% MA experimental group } \\
\hline & CTR diet & MA diet & CTR diet & MA diet \\
\hline $\begin{array}{l}\text { Tumor weight } \\
\text { Significance }\end{array}$ & $1,323 \pm 251.4$ & $1,019.3 \pm 178.6$ & $941.3 \pm 231.4$ & $1,235.6 \pm 208.4$ \\
\hline
\end{tabular}

CTR, control; MA, mead acid; NS, not significant.
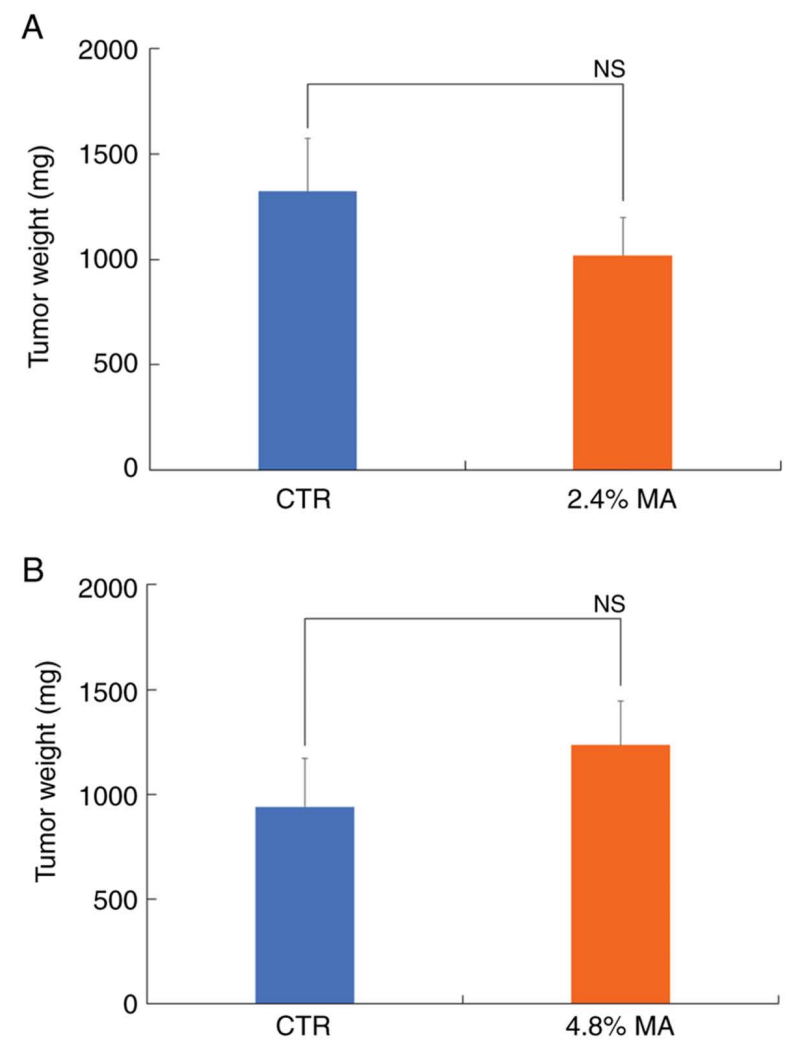

Figure 3. The final average of DMBA-induced breast tumor weight in CTR diet group vs. MA diet group. (A) The $2.4 \%$ MA experimental group; (B) the $4.8 \%$ MA experimental group. No significant differences were observed between the CTR and MA diet $(2.4 \%$ MA and $4.8 \%$ MA experimental groups, respectively). NS, not significant; CTR, control; MA, mead acid.

ultra-processed sugary products, sulforaphane, vitamin D, calcium, soy isoflavone) (18,22-25). Recently, the influence of the quality of daily foods on breast cancer has attracted considerable attention. For example, Lo et al reported that the consumption of red meat increases the risk of developing breast cancer (22). A large-scale cohort study carried out in France revealed that the intake of ultra-processed sugary products was associated with the incidence of breast cancers (23). By contrast, sulforaphane extracted from broccoli, vitamin D, calcium and soy isoflavone have been reported to function as possible cancer-preventive agents $(18,24,25)$. Therefore, it seems that the constituents of foods consumed on a daily basis play a role in breast carcinogenesis.

The present study investigated the concentration of fatty acids and its influence on breast cancer. Previous studies have

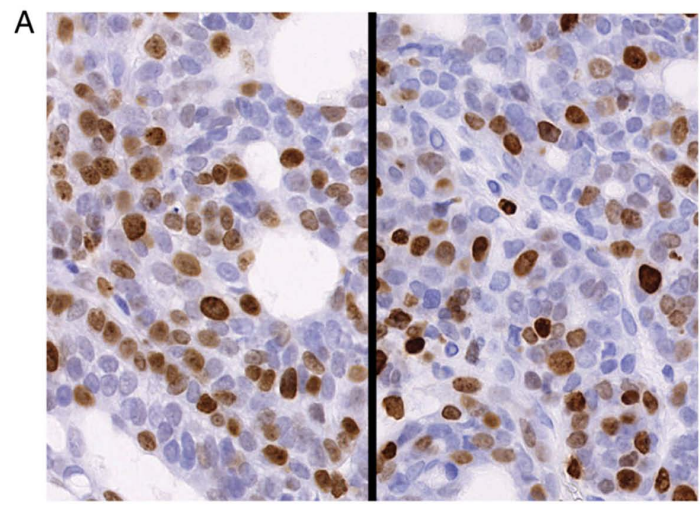

B

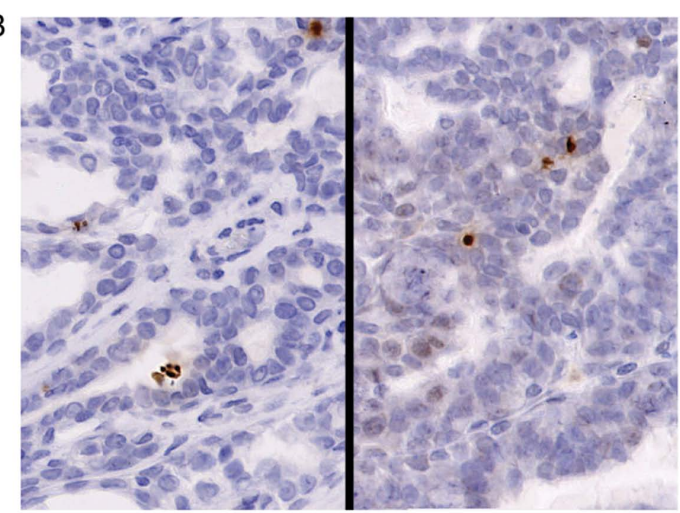

Figure 4. Immunohistochemical findings of (A) Ki-67 (right panel, CTR diet group; left panel, $2.4 \%$ MA diet group) and (B) $\gamma$-H2A.X (right panel, CTR diet group; left panel, $2.4 \%$ diet group) labeling index. From these findings, there were no distinct differences between CTR diet group and 2.4\% MA diet group as regards cell kinetics and cell death. CTR, control; MA, mead acid.

examined the influence of fatty acid composition on breast carcinogenesis. The majority of previous studies have focused on n-3 PUFA and/or n-6 PUFA. The effects of n-9 PUFA were previously examined against breast cancer and the data indicated that MA inhibited the growth of luminal A type breast cancer by suppressing the expression of VEGFR. In addition, MA inhibited the growth of transplanted luminal A type breast cancer cells in nude mice and their metastasis to the lymph nodes (12). MA also inhibited the formation of MNU-induced breast cancer in rats (13). Based on these data, MA appeared to be beneficial for the suppression of breast cancer. However, it has been reported that the effects of MA vary depending on the target cells (14). Heyd and Eynard examined the effects of MA on 3 different cancer cell lines (T-24; bladder cancer cell line, MCF-7; breast cancer cell line 
Table III. Cell kinetics of DMBA-induced breast cancer (\%).

\begin{tabular}{|c|c|c|c|c|}
\hline \multirow[b]{2}{*}{ Examination } & \multicolumn{2}{|c|}{$2.4 \%$ MA experimental group } & \multicolumn{2}{|c|}{ 4.8\% MA experimental group } \\
\hline & CTR diet & MA diet & CTR diet & MA diet \\
\hline Ki-67 LI & $46.5 \pm 8.6$ & $35.1 \pm 3.8$ & $33.2 \pm 3.3$ & $26.0 \pm 3.5$ \\
\hline$\gamma \mathrm{H} 2 \mathrm{~A} . \mathrm{X}$ LI & $0.7 \pm 0.3$ & $0.6 \pm 0.2$ & $0.7 \pm 0.3$ & $0.6 \pm 0.2$ \\
\hline Significance & \multicolumn{2}{|c|}{ NS } & \multicolumn{2}{|c|}{ NS } \\
\hline
\end{tabular}

CTR, control; MA, mead acid; LI, labeling index; NS, not significant.
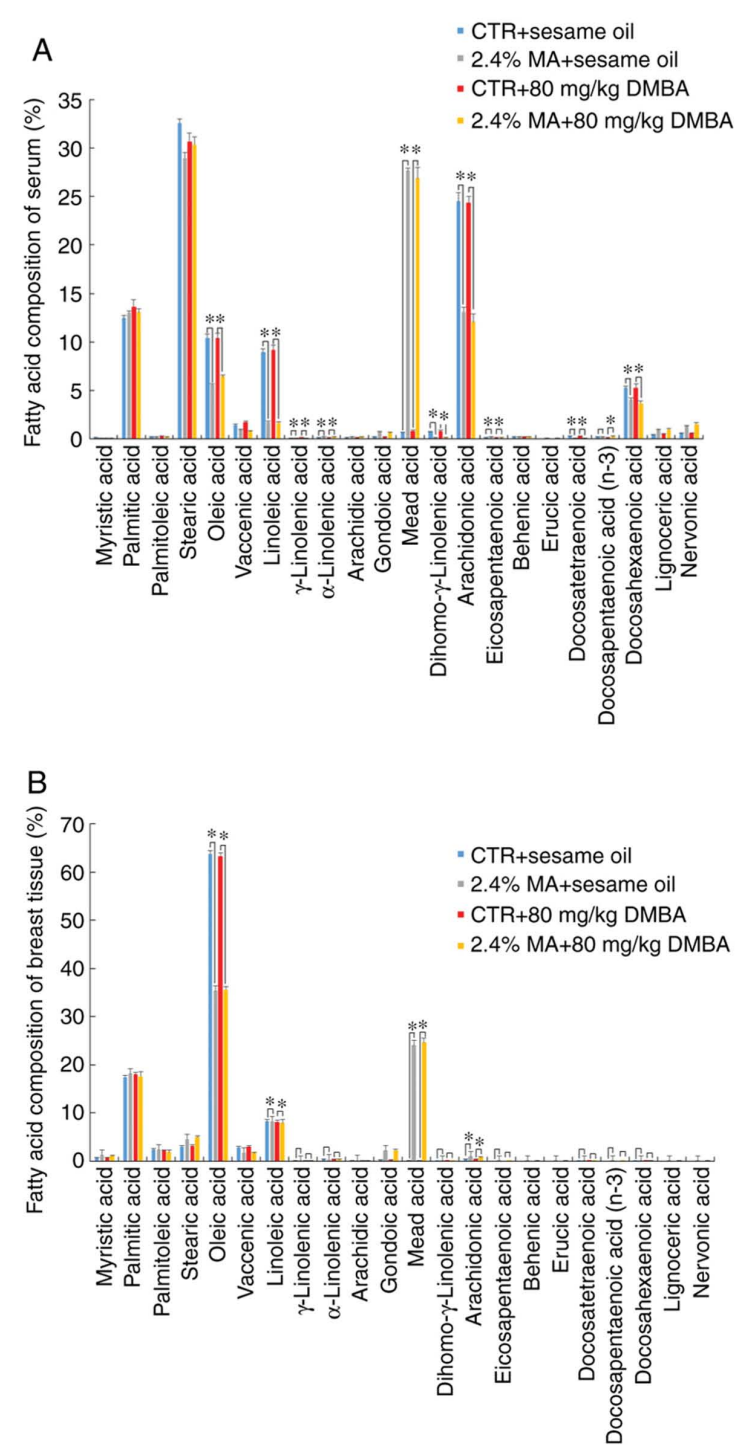

Figure 5. Comparison of fatty acid composition in animals fed either the $2.4 \%$ MA diet or CTR diet for 13 weeks, and treated with or without DMBA. Fatty acid composition in (A) serum and (B) breast tissue. Fatty acid composition in serum and breast tissue reflected the differences in the contents of fatty acid induced by the different diets. ${ }^{*} \mathrm{P}<0.05$. CTR, control; MA, mead acid; DMBA, 7,12-dimethylbenz[a]anthracene.

and HRT-18; colon cancer cell line) (14). In their study, MA suppressed the cell proliferation of MCF-7, but promoted the growth of HRT-18 cells. When the cells were seeded at a high density, MA increased the cell proliferation of T-24 cells,
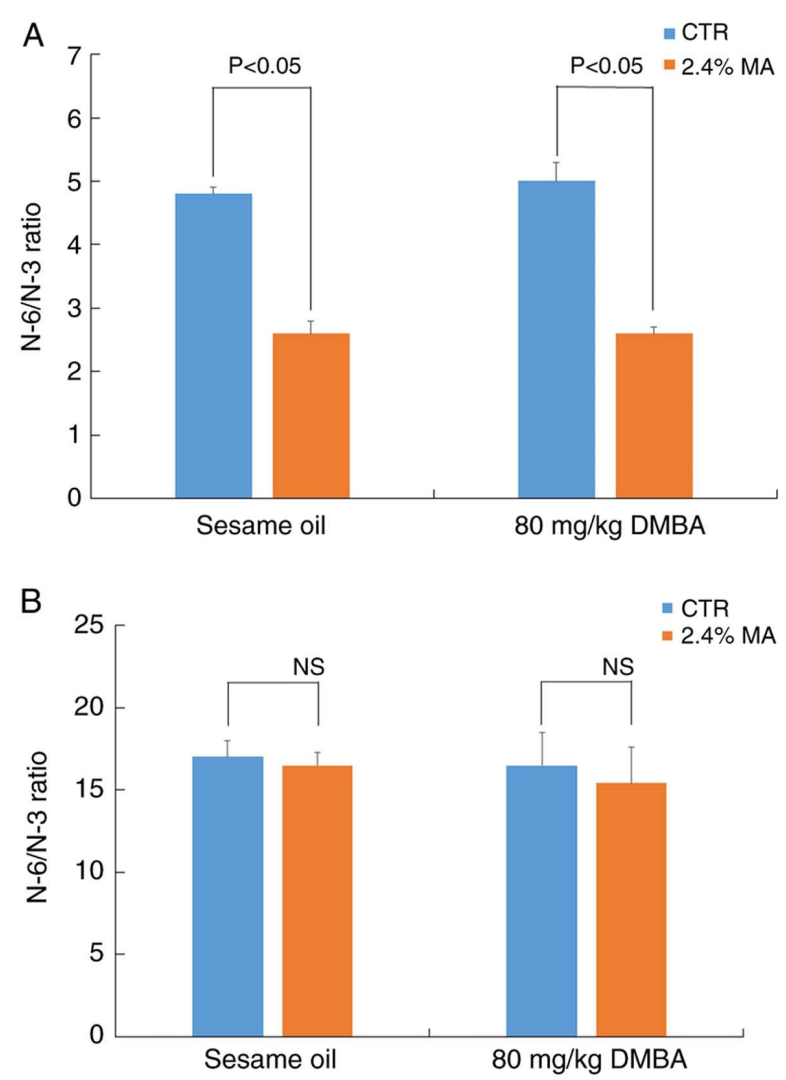

Figure 6. N-6/N-3 ratio in serum and breast tissue of animals fed the $2.4 \%$ MA diet or CTR diet, with or without DMBA treatment. (A) The MA diet significantly decreased the $\mathrm{N}-6 / \mathrm{N}-3$ ratio in serum $(\mathrm{P}<0.05)$. (B) On the other hand, no significant differe nces were observed in breast tissue. NS, not significant; CTR, control; MA, mead acid; DMBA, 7,12-dimethylbenz[a] anthracene.

while the opposite results were noted at a low cell density. In their study, MA treatment also increased the expression levels of E-cadherin in the MCF-7 cell line (14). However, E-cadherin expression levels has not been found to be altered in the breast cancer cell line, KPL-1 (12). Moreover, our previous studies indicated that MA inhibited the expression levels of VEGFR, but did not affect angiogenesis $(12,13)$. By contrast, Hamazaki et al measured angiogenesis by a co-culture system using umbilical vein endothelial cells and human diploid fibroblasts with or without MA and reported that MA inhibited angiogenesis (26). Moreover, Eynard et al reported that MA inhibited the expression of E-cadherin and stimulated the growth of squamous cell carcinoma (27). 
The effects of MA on different cancer types vary greatly and only 4 studies have been previously published examining the association between MA and cancer cell progression (12-14,27). In vivo studies were performed using two carcinogens, which resulted in the induction of breast cancer formation via different mechanisms of action. MNU is a direct-acting alkylating agent that interacts with DNA and yields a variety of conversion products (28). These products induce breast cancer by causing DNA damage, DNA methylation and several genetic abnormalities. DMBA was the carcinogen used in the present study that could induce cancer progression through the formation of DNA adducts and DNA damage $(29,30)$.

In the present study, the MA diet did not suppress the incidence of breast cancer, although the Ki-67 labeling index was lower in the MA groups compared with that of the CTR diet group. The N-6/N-3 ratio in serum in the MA diet group indicated a significant decrease compared with that in the CTR diet group, whereas significant changes were not detected in the breast tissues in both groups. However, it has been previously reported that a lower ratio N-6/N-3 in the serum is associated with a lower incidence of breast cancer in humans (31). The reason for the discrepancy between these studies is not clear; however, it may be associated with the use of the two different carcinogens, MNU and DMBA.

In conclusion, the present study reported that the parameters tumor incidence, Ki-67 labeling index and $\gamma$-H2A.X-labeling index were not significantly affected by the specific MA diets in female Sprague-Dawley rats with DMBA-induced breast cancer. To further clarify the effects of MA on breast carcinogenesis, further investigations with different experimental breast cancer models are thus recommended.

\section{Acknowledgements}

The authors would like to thank Dr Robert R. Maronpot, Maronpot Consulting, LLC, for his excellent scientific advice and English grammar editing.

\section{Funding}

No funding was received.

\section{Availability of data and materials}

All data generated or analyzed during this study are included in this published article or are available from the corresponding author on reasonable request.

\section{Authors' contributions}

YK, MYo, ATs and KY made substantial contributions to the conception and design of the study. YK, MYo, YM, TY, MYu, $\mathrm{CK}$ and ATa were involved in data acquisition, data analysis and interpretation. $\mathrm{YK}$ and $\mathrm{KH}$ were involved in fatty acid analysis. ATs and KY drafted the article or critically revised it for important intellectual content. All authors gave the final approval of the version to be published and all author agree to be accountable for all aspects of the work to ensure that questions regarding the accuracy or integrity of the work are appropriately investigated and resolved.

\section{Ethics approval and consent to participate}

The study protocol and animal procedures were approved by the Animal Care and Use Committee of Kansai Medical University, Hirakata, Osaka, Japan (permit no. 13-060).

\section{Patient consent for publication}

Not applicable.

\section{Competing interests}

The authors declare that they have no competing interests.

\section{References}

1. Colditz G and Chia KS: Invasive breast carcinoma: Introduction and general features. In: World Health Organization, Pathology $\&$ Genetics. Tumours of the Breast. Lakhani SR, Ellis IO, Schnitt ST, Tan PH and van de Vijver MC (eds). IARC Press, Lyon, pp14-31, 2012.

2. Adami HO, Signorello LB and Trichopulos D: Towards an understanding of breast cancer etiology. Semin Cancer Biol 8: 225-262, 1998.

3. Freedman LS, Kipnis V, Schatzkin A and Potischman N: Methods of epidemiology: Evaluating the fat-breast cancer hypothesis-comparing dietary instruments and other developments. Cancer 14: 69-74, 2002.

4. Senzaki H, Tsubura A and Takada H: Effect of eicosapentaenoic acid on the suppression of growth and metastasis of human breast cancer cells in vivo and in vitro. World Rev Nutr Diet 88: 117-125, 2001.

5. Yamamoto D, Kiyozuka Y, Adachi Y, Takada H, Hiroki K and Tsubura A: Synergistic action of apoptosis induced by eicosapentaenoic acid and TNP-470 on human breast cancer cells. Breast Cancer Res Treat 55: 149-169, 1999.

6. VanderSluis L, Mazurak VC, Damaraju S and Field CJ: Determination of relative efficacy of eicosapentaenoic acid and docosahexaenoic acid for anti-cancer effects in human breast cancer models. Int J Mol Sci 18: 2607, 2017.

7. Senzaki H, Iwamoto S, Ogura E, Kiyozuka Y, Arita S, Kurebayashi J, Takada H, Hiroki K and Tubura A. Dietary effects of fatty acids on growth and metastasis of KPL-1 human breast cancer cells in vivo and in vitro. Anticancer Res 18: 1621-1627, 1998.

8. Chung NW, Wu CT, Chen DR, Yeh CY and Lin C: Hight levels of arachidonic acid and peroxisome proliferator-activated receptor-alpha in breast cancer tissues and associated with promoting cancer cell proliferation. J Nutr Biochem 24: 274-281, 2013.

9. Mead JF and Slaton WH Jr: Metabolism of essential fatty acids. III. Isolation of 5,8,11-eicosatrienoic acid from fat-deficient rats. J Biol Chem 219: 705-709, 1956.

10. Fulco AJ and Mead JF: Metabolism of essential fatty acids. VIII. Origin of 5,8,11-eicosatrienoic acid in the fat-deficient rat. J Biol Chem 234: 1411-1416, 1959.

11. Ichi I, Kono N, Arita Y, Haga S, Arisawa K, Yamano M, Nagase M, Fujiwara Y and Arai H: Identification of genes and pathways involved in the synthesis of Mead acid (20:3 n-9), an indicator of essential fatty acid deficiency. Biochim Biophys Acta 1841: 204-213, 2014

12. Kinoshita Y, Yoshizawa K, Hamazaki K, Emoto Y, Yuri T, Yuki M, Shikata N, Kawashima H and Tsubura A: Mead acid inhibits the growth of KPL-1 human breast cancer cells in vitro and in vivo. Oncol Rep 32: 1385-1394, 2014.

13. Kinoshita Y, Yoshizawa K, Hamazaki K, Emoto Y, Yuri T, Yuki M, Kawashima H, Shikata N and Tsubura A: Dietary effects of mead acid on $N$-methyl- $N$-nitrosourea-induced mammary cancers in female Sprague-Dawly rats. Biomed Rep 4: 33-39, 2016. 
14. Heyd VL and Eynard AR: Effects of eicosatrienoic acid (20:3 n-9, Mead's acid) on some premalignant-related properties of three human cancer cell lines. Prostaglandins Other Lipid Mediat 71: $177-188,2003$.

15. Tsubura A, Izuno Y, Shoji T, Kusunose $\mathrm{N}$ and Morii S: Influence of strain and sex on the local development of mammary tumors induced by direct application of DMBA powder to rat mammary glands. Acta Pathol Jpn 40: 9-13, 1990.

16. Sakuradani E, Kameda N, Hirano Y, Nishihara M, Kawsashima H, Akimoto K, Higashiyama K, Ogawa J and Shimizu S: Production of 5,8,11-eicosatrienoic acid by a delta5 and delta6 desaturation activity-enhanced mutant derived from a delta12 desaturation activity-defective mutant of Mortierella alpine 1S-4. Appl Microbiol Biotecnol 60: 281-287, 2002.

17. Kawamura I, Mizota T, Kondo N, Shimomura K and Kohsaka M: Antitumor effects of droloxifene, a new antiestrogen drug, against 7,12-dimethylbenz (a) anthracence-induced mammary tumor in rats. Japan J Pharmacol 57: 215-224, 1991.

18. Kanematsu S, Yoshida K, Uehara N, Miki H, Sasaki T, Kuro M, Lai YC, Kimura A, Yuri T and Tsubura A: Sulforaphane inhibits the growth of KPL-1 human breast cancer cells in vitro and suppress the growth and metastasis of orthotopically transplanted KPL-1 cells in female athymic mice. Oncol Rep 26: 603-608, 2011.

19. Rodon CE, Weyemi U, Parekh PR, Huang D, Burrell AS and Bonner WH: $\gamma \mathrm{H} 2 \mathrm{~A}$.X and other histone post-translational modifications in the clinic. Biochim Biophys Acta 1819: 743-756, 2012.

20. Bligh EG and Dyer WJ: A rapid method of total lipid extraction and purification. Can J Biochem Physiol 3: 911-917, 1959.

21. Bruzzi P, Green SB, Byar DP, Brinton LA and Schairer C: Estimating the population attributable risk for multiple risk factors using case-control data. Am J Epidemiol 122: 904-914, 1985.

22. Lo JJ, Park YM, Sinha R and Sandler DP: Association between meet consumption and risk of breast cancer: Findings from the Sister Study. Int J Cancer 146: 2156-2165, 2020.
23. Fiolet T, Srour B, Sellem L, Kesse-Guyot E, Allès B, Mèjean C, Deschasaux M, Fassier P, Latino-Martel P, Beslay M, et al: Consumption of ultra-processed foods and cancer risk: Results from NutriNet-Sanè prospective cohort. BMJ 360: k322, 2018.

24. Chen P, Hu P, Xie D, Wang F and Wang H: Meta-analysis of vitamin $\mathrm{D}$, calcium and the prevention of breast cancer. Breast Cancer Res Treat 121: 469-477, 2010.

25. Moorehead RA: Rodent models assessing mammary tumor prevention by soy or soy isofravones. Genes (Basel) 10: 566, 2019.

26. Hamazaki T, Nagasawa $Y$, Hamazaki $\mathrm{K}$ and Itomura $\mathrm{M}$ : Inhibitory effect of 5,8,11-eicosatorienoic acid on angiogenesis. Prostaglandins Leukot Essent Fatty Acids 86: 221-224, 2012.

27. Eynard AR, Jiang WG and Mansel RE: Eicosatrienoic acid $(20: 3 \mathrm{n}-9)$ inhibits the expression of E-cadherin and desmoglein in human squamous cell carcinoma in vitro. Prostaglandins Leukot Essent Fatty Acids 59: 371-377, 1998.

28. Tsubura A, Yoshizawa K and Sasaki T: Methylnitrosourea. In Waxler P (Ed.), Encyclopedia of Toxicology, 3rd edition. Elsevier Inc., Academic press vol. 3, pp. 321-323, 2014.

29. Watabe T, Ishizuka T, Isobe M and Ozawa N: A 7-hydoroxymethyl sulfate ester as an active metabolite of 7, 12-dimethyl[alpha] anthracene. Science 215: 403-405, 1982.

30. Lee HJ, Lee YJ, Kang CM, Bae S, Jeoung D, Jang JJ, Lee SS, Cho CK and Lee YS: Differential gene signatures in rat mammary tumors induced by DMBA and those induced by tractionated gamma radiation. Radiat Res 170: 579-590, 2008.

31. Okuyama $\mathrm{H}$, Kobayashi $\mathrm{T}$ and Watanabe S: Dietary fatty acids-the N-6/N-3 balance and chronic elderly diseases. Excess the linoleic acid and relative N-3 deficiency syndrome seen in Japan. Prog Lipid Res 35: 409-457, 1996.

(7) $\Theta$ This work is licensed under a Creative Commons Attribution-NonCommercial-NoDerivatives 4.0 International (CC BY-NC-ND 4.0) License. 